\title{
A Review of Second Language Structural Priming Research
}

\author{
WANG Li \\ Qingdao University of Science and Technology, Qingdao, China
}

\begin{abstract}
Structural priming reveals a new horizon in the research of bilingual syntactic representations. It facilitates the interpretation of bilingual syntactic transfer and syntactic misuse. So structural priming in L2 (second language) is practically meaningful for L2 teaching and learning. This paper attempts to review the within-language and between-language priming, as well as interaction studies to examine how far research has delved into this field and suggestions for future research are provided.
\end{abstract}

Keywords: structural priming, within-language, between-language, interaction

\section{Introduction}

Research shows that language users tend to employ a specific syntactic structure after they have had a previous experience with that structure (in contrast to an equally acceptable structure). This phenomenon is usually referred to as structural priming. It has been examined in L1 (first language) processing and acquisition, as well as in L2 processing and learning. The findings of cross-linguistic studies have revealed that syntactic priming occurs cross-linguistically. Investigation in this field focuses on the facilitative effect that previous exposure to a certain structure has on subsequent language production, with only a few studies explore whether previous experience promotes the comprehension of target structures following the prime. The goal of the present paper is to examine the research of cross-linguistic structural priming, with special attention being paid to structural priming in L2 processing and learning.

\section{Role of Syntactic Priming in L2 Processing and Learning}

Subjects who participate in L2 studies are generally still in the process of learning their L2 via formal classroom instruction. Their L2 proficiency, consequently, has not reached their ultimate achievement. Thus, unlike L1 language production research which investigated alternation between two equivalently appropriate and totally-acquired syntactic structures, studies in L2 processing and learning center on learners' alternation between such structures as grammatical and ungrammatical structures, developmentally simple and complex syntactic structures, and appropriate versus inappropriate ones to investigate the relationship between L2 development and structural priming.

The question that is addressed in present L2 structural priming research is whether syntactic priming facilitates L2 development. L2 development is of essential significance in L2 research. In L2 processing and production studies, the materials, or the alternating structures employed in priming research may be equally acceptable in a learner's interlanguage but not equally in line with the target language norms. Thus, to judge whether syntactic priming has occurred, researchers expose language users to both of the alternating structures

WANG Li, lecturer, master, English Department, Qingdao University of Science and Technology. 
in the priming phase, and calculate the frequency that L2 learners produce them through targets. Tasks usually used in syntactic priming research include picture description, sentence recall, sentence completion, and scripted interaction.

\section{Within-Language Priming}

Within-language priming research found that priming occurred in L2 speech production. Evidence of structural priming in both datives (Gries \& Wulff, 2005; McDonough, 2006; Schoonbaert, Hartsuiker, \& Pickering, 2007) and alternation in word order between adjective-noun phrases and relative clauses (Bernolet, Hartsuiker, \& Pickering, 2007) are found in previous research. McDonough and Machey (2008) elaborate that structural priming can promote the production of the developmentally advanced language structure and suppress the production of the alternative structure in their interlanguage, which is considered to be a potential role of structural priming. Gries and Wulff (2005) studied the occurrence of syntactic priming in L2 speech production. Participants in their research are 64 German university students who learn English as L2. Sentence completion task results uncovered that priming occurred for both double-object and prepositional datives. Both Schoonbaert, Hartsuiker, and Pickering (2007) and McDounough (2006) employed the scripted interlocutor tasks to examine dative priming, finding that priming occurred in L2. In his study, McDounough (2006) chose L2 learners of English with various L1 language background as his subjects and found that priming occurred for prepositional datives only. A more interesting finding in this field of research comes from McDounough and Mackey (2008). They explored the relationship between syntactic priming and ESL (English as a Second Language) question development via scripted interlocutor task and found that priming was associated with question development, thus proving that structural priming can facilitate L2 learners' production and enhance their L2 proficiency.

\section{Between-Language Priming}

Between-language priming can help to deepen our understanding of the organization of L1-L2 syntactic information. Structural priming has been employed to test whether, for bilinguals, syntactic representations are stored separately or shared. The shared-syntax account indicates that cross-language priming would occur, as activation of the syntactic structure in one language would facilitate production of the related structure in the second language.

The findings of between-language priming studies (Desmet \& Declercq, 2006; Loebell \& Bock, 2003; Meijer \& Fox Tree, 2003; Schoonbaert, Hartsuiker, \& Pickering, 2007) have demonstrated that syntactic priming occurs cross-linguistically, which supports the shared-syntax account. Research of dative priming shows that cross-linguistic priming occurred in response to single-verb primes (Salamoura \& Williams, 2006) and it was dependent on an overlap between constituent order and thematic roles (Salamoura \& Williams, 2007). Another line of research was carried out around the priming of passives. These studies revealed that priming of passives occurred between languages (Hartsuiker, Pickering, \& Veltkamp, 2004) and more passives occurred when the learners' prompts had the same verbs produced by the scripted interlocutor (Kim \& McDounough, 2008).

Another research conducted by Desmet and Declercq (2006) examines the occurrence of syntactic priming related to hierarchical tree configuration. Eighty-four university students participated in the relative clause attachment test via a sentence completion task. They concluded that priming occurred independent of 
subcategorization frames or individual syntactic rules.

Between-language priming is dependent on the theoretical basis that L1 and L2 syntax share the same representation. If there is a complete sharing of syntactic representation of L1 and L2, there will be no difference between the degree of within-language priming and between-language priming. Divergence of findings, however, exists in present studies. Bernolet, Hartsuiker, and Pickering (2007) found that cross-linguistic priming occurred only when the L1 and L2 had similar word order, that is, greater within-language priming occurred than between-language priming. Thereby, we can conclude that there is no complete sharing of syntactic representation between L1 and L2. However, the degree of priming may be influenced by various factors, such as testing material and structure, which need further exploration. Besides, the degree of priming may change with the development of learners' L2 proficiency.

\section{Implicitness of Syntactic Priming}

Implicit learning refers to the incidental tuning or adjustment of the tendencies of a processing system as a function of experience (Ferreira \& Bock, 2006). The implicit learning account in structural priming demonstrates that structural priming is a form of implicit, production-specific procedural learning. This learning process makes language processing system adjusted to previous experience with the target language. Evidence in favor of the implicit learning account center upon the points that structural priming is long-lasting (Bock \& Griffin, 2000), learning (Hartsuiker \& Kolk, 1998), and implicit (Bock, Loebell, \& Morey, 1992). In other words, syntactic priming is independent of explicit memory. It is an unconscious process in which language learners grasp the key of abstract information processing. Results of studies show the persistence of structural priming effects, indicating its nature of implicit learning.

\section{Interaction and Alignment in Priming Research}

L2 development is facilitated by interactions which combine input, internal learner capacities, and language production. Alignment in these interactions is a socio-cognitive process evolved from constant coordination and adaptation in the process of interaction, whether it is interaction between learners or between learners and the text read. L2 classroom researchers (Havranek, 2002; Panova \& Lyster, 2002; Sheen, 2004) have investigated L2 teachers' interactional feedback in response to learners' non-standard language forms and whether various types of interactional feedback are more likely to result in learner uptake. This line of research helps to further our understanding of the nature and effect of teachers' feedback to students. Their studies, however, focus only on those learner responses in the immediate wake of the teacher's feedback move.

WANG and WANG (2014) investigated how L2 writing is affected by alignment, showing that alignment exists in writing when participants performed the English-version continuation task, as they used more lexical items in the text provided and thus made significantly fewer errors. In contrast, their performance on the Chinese-version continuation task which activated the learners' L1 contextual knowledge elicited significantly more L1 transfer errors. Their study makes structural priming research delve into the area further by combining production with comprehension on syntax level and discourse level. It indicates ways to curb L1 transfer by maximizing L2 involvement and providing exact positive input followed by production task. However, as they have pointed out, there is still more to be examined at the syntactic level of this alignment effect. 


\section{Conclusion}

A brief review of structural priming research conducted in L2 language processing and learning reveals that we are getting closer to the nature of bilingual syntactic representations. However, there are still issues needing further exploration. Researchers may gain greater insight into the mechanisms involved in syntactic priming as well as its role in language processing and learning providing we target other language structures and other populations more frequently. With regard to experimental task, researchers can incorporate more discourse-level elements into structural priming research, along with the study in sentence-level language production.

For interaction research, we can probe the question whether individual differences, such as aptitudes and working memory capacity, might possibly help L2 language learners benefit from the implicit learning processes intertwined with structural priming. As for L2 classroom research, we can still further explore whether certain types of interactional feedback facilitate primed production and explore teacher-learner as well as learner-learner interaction.

\section{References}

Bernolet, S., Hartsuiker, R., \& Pickering, M. (2007). Shared syntactic representations in bilinguials: Evidence for the role of word-order repetition. Journal of Experimental Psychology: Learning, Memory, and Cognition, 33, 931-949.

Bock, K., Loebell, H., \& Morey, R. (1992). From conceptual roles to structural relations: Bridging the syntactic cleft. Psychological Review, 99, 150-171.

Bock, J. K., \& Griffin, Z. M. (2000). The persistence of structural priming: Transient activation or implicit learning? Journal of Experimental Psychology: General, 129, 177-192.

Desmet, T., \& Declercq, M. (2006). Cross-linguistic priming of syntactic hierarchical configuration information. Journal of Memory and Language, 54, 610-632.

Ferreira, V., \& Bock, J. K. (2006). The functions of structural priming. Language and Cognitive Processes, 21, 1011-1029.

Gries, S. T., \& Wulff, S. (2005). Do foreign language learners also have constructions? Evidence from primig, sorting and corpora. Annual Review of Cognitive Linguistics, 3, 182-200.

Hartsuiker, R. J., Pickering, M. J., \& Veltkamp, E. (2004). Is syntax separate or shared between languages? Psychological Science, 15, 409-414.

Hartsuiker, R. J., \& Kolk, H. H. J. (1998). Syntactic persistence in Dutch. Language and Speech, 41, 143-184.

Havranek, G. (2002). When is corrective feedback most likely to succeed? International Journal of Educational Research, 37, 255-270.

Kim, Y., \& McDounough, K. (2008). Learners' production of passives during syntactic priming activities. Applied Linguistics, 29, $149-154$

Loebell, H., \& Bock, K. (2003). Structural priming across languages. Linguistics, 41, 791-824.

Mc Donough, K. (2006). Interaction and syntactic priming: English L2 speakers' production of dative constructions. Studies in Second Language Acquisition, 28, 179-207.

McDonough, K., \& Mackey, A. (2008). Syntactic priming and ESL question development. Studies in Second Language Acquisition, 30, 31-47.

Meijer, P. J. A., \& Fox Tree, J. E. (2003). Building syntactic structures in speaking: A bilingual exploration. Experimental Psychology, 50, 184-195.

Panova, I., \& Lyster, R. (2002). Patterns of corrective feedback and uptake in an adult ESL classroom. TESOL Quarterly, 36, 573-595.

Salamoura, A., \& Williams, J. N. (2006). Lexical activation of cross-language syntactic priming. Bilingualism: Language and Cognition, 9, 299-307.

Salamoura, A., \& Williams, J. N. (2007). Processing verb argument structure across languages: Evidence for shared representations in the bilingual lexicon. Applied Psycholinguistics, 28, 627-660. 
Schoonbaert, S., Hartsuiker, R. J., \& Pickering, M. J. (2007). The representation of lexical and syntactic information in bilinguals: Evidence from syntactic priming. Journal of Memory and Language, 56, 153-171.

Sheen, Y. (2004). Corrective feedback and learner uptake in communicative classrooms across instructional settings. Language Teaching Research, 8, 263-300.

WANG, C. M., \& WANG, M. (2014). Effect of alignment on L2 written production. Applied Linguistics, 1, 1-25. 